\title{
The Impact of the COVID-19 Pandemic on Family Engagement
}

\author{
Libby Daggers, Texas A\&M University \\ Mark Pontious, Miami University \\ Kimberly Sterritt, The University of Alabama \\ Benjamin Williams, Georgia State University
}

While family engagement professionals are accustomed to engaging a remote population with high expectations, the COVID-19 pandemic brought challenges, opportunities for innovation, and even higher expectations from families. This article collects experiences from four family engagement colleagues, highlighting families' experiences throughout the pandemic, its impact on family engagement, and how this time period may shape institutional approaches to family engagement going forward.

Keywords: family engagement, university response, COVID impacts, communication

The relationship between institutions and their students' families is in a constant state of evolution. Colleges and universities once operated under an in loco parentis model, where the focus was on student behavior and institutions assumed the role of parents for discipline (Forbes, 2001). In this model, students, who were not considered adults, needed careful monitoring of faculty and administrators (Forbes, 2001). Since the early 1990s, families' involvement in their students' experiences has steadily increased due to the rising cost of higher education and the introduction of various technologies that allow families and students to keep closely connected, often communicating multiple times per week (Gentzler et al., 2011). Families are likely to be involved financially and emotionally in their students' experience, which contributes to the increased levels of communication and engagement (Carney-Hall, 2008). In response, institutions have adopted the consortio cum parentibus model that views parents and family members as partners of the university (Kiyama et al., 2015). Institutions have developed offices and identified staff dedicated to services to support family engagement throughout the collegiate experience. These offices provide targeted communication, special events, involvement opportunities, and a direct connection to university staff (Savage, 2008). Within the past decade, many of these offices have expanded their services and branding to be more inclusive of all family structures instead of exclusively serving those in a parental role.

The shift in the family's role in a student's collegiate career also means heightened expectations from families. Frequently, family engagement offices have responsibility for quickly addressing families' concerns regardless of the source while also creating meaningful and engaging concurrent orientation programming for families and stand-alone events like Family Weekend. Families expect a high level of service and professionalism in all interactions with the college or university, and those expectations did not change during the COVID-19 pandemic. For example, the timeliness of communication regarding COVID-19 was a concern for many families (TorchStar Education, 2020). In a recent study, 53\% of parents wanted university communication at least once 
per month. Nearly half (46\%) wanted to hear as often as needed or when the campus had important updates to share (Monroe et al., 2020). Families were eager for information, and family engagement professionals bore the responsibility to provide it. Though necessary, the continual need to meet these expectations can be taxing, especially in times of crisis.

Mullendore and Banahan (2005) recommended building orientation programs that model Maslow's hierarchy of needs by addressing core student services like dining, housing, and safety before tackling student engagement and belonging. During the pandemic, this approach proved useful, and initial communications were designed to address student health and safety concerns. Family engagement professionals must know how to best communicate information with the remote population they serve, primarily through email, digital publications, and webinars. While many communication and engagement methods did not change during the pandemic, the content shifted to address health and safety concerns before other campus information. The day-to-day approach to family engagement work did not change due to COVID-19 since there was an existing foundation for using technology to communicate and engage our family populations. However, the pandemic exacerbated families' concerns, and family engagement professionals were on the frontlines of institutional service provision.

This article collects the experiences of four family engagement professionals working in four-year, public universities with dedicated parent and family programs and services. The institutions differ in student population demographics and size, geographic location, state-driven mandates, and institutional responses to COVID-19, as the following descriptions make clear

- Texas A\&M University is a predominately white institution (PWI) located in a southern state, enrolling 56,000 students. The university allowed students on campus for fall 2020 , and more than $50 \%$ of courses were offered face to face (with a virtual option). State mandates for mask wearing were in place.

- The University of Alabama is a PWI with 38,000 students and located in the Southeast. Alabama allowed students to live on campus for fall 2020 with extremely limited face-to-face courses. A state mask mandate was in place, but most other restrictions were lifted in May 2020.

- Georgia State University is a minority-serving institution (MSI), enrolling 54,000 students across six campuses located in the Southeast. Limited numbers of students were living on campus with limited face-to face-courses. A state mask mandate and some restrictions/limitations on large gatherings were in place.

- Miami University is a PWI located in the Midwest, enrolling 20,000 students. The university allowed students to live on campus for fall 2020, with extremely limited face-to-face courses. State mandates for mask wearing and crowd-size restrictions were in place.

Despite the local and institutional differences, our collective experiences navigating COVID-19 were remarkably similar. We acknowledge that the experiences of family engagement professionals at smaller, twoyear, and private institutions may vary from those reported here. Each author effectively communicated with a remote population to provide timely information to concerned families, used creative programming skills to implement virtual programs and connections, and advocated on behalf of families to institutional leadership and campus partners. In this article, we reflect on the past year through the lens of family engagement professionals and the anticipated long-term effects of COVID-19 for family engagement in higher education, including opportunities to better engage families of our students. 


\section{Through the Lens of Family Concerns and Engagement}

\section{Spring Semester 2020}

COVID-19 became the top public health concern for the United States in March 2020, a month traditionally dominated by anticipating, enjoying, and recovering from spring break. Instead, it was a time for unprecedented and difficult decisions for university leadership. The decisions varied from "Students, pack all your belongings within 24 hours and don't return until further notice" to "Have a fun spring break. We'll email you later if you should come back and keep your belongings for the time being." Institutions began to announce plans to transition to online instruction during the week of March 9. By the week of March 23, more than 1,000 campuses had transitioned to online instruction. Within another week, over 1,300 institutions across all 50 states had abruptly transitioned to online instruction for the remainder of the semester (The College Crisis Initiative, 2020).

In a time of the heightened uncertainty caused by the pandemic, families demanded information from institutions as soon as possible in a rapidly changing situation. Their demands resulted in a high quantity of communication, with changing messages that could be perceived as inconsistent by families; vague communication to reduce the possibility of changing the message later; or delayed communication. Family engagement professionals, when possible, advocated for quicker and clearer communication to provide support and reassurance for families. Parent and family hotlines, along with phone lines across the institution and including the president's office, were flooded by families seeking answers to their questions. University leadership heard, often loudly, the concerns and needs of their family constituents. Family engagement professionals were in the unenviable position of communicating and defending decisions in which they played no role and of absorbing the heated concerns on behalf of the institution.

Once the shock of the transition to online instruction began to fade, families had a front-row seat to observe their students' journey as online learners while also tackling the challenge of supporting a student in the virtual learning environment. With the up close and personal view of the online academic experiences came a critical eye and concerns about their students' ability to successfully complete the spring term. Families sought clarity about pass/fail grading options, demanded that students receive quick responses from faculty, and questioned the quality of the online educational experience provided in some classes. Family engagement professionals continued to field these concerns while also proactively providing tips on helping students manage distance learning, supporting students through finals, and coaching students through the grief of unmet expectations. Due to the closer proximity, families often increased their involvement, jumping in to "fix" the most mundane issues that during a normal semester would have barely registered on the student's radar, let alone that of a family member.

Families with students on each end of the college experience had unique and heightened concerns. Families of new students lamented that their students were not getting the full first-year experience and, as a result, were also not prepared to transition to online learning. On the other end, families of graduating seniors grieved alongside students about the lost rites of passage and increased uncertainty about students' job searches. Campuses struggled to determine what to do about commencement ceremonies, and most offered virtual ceremonies in lieu of in-person events. Again, family engagement professionals sprang into action, providing ways families could celebrate their graduate while also advocating for increased acknowledgment of graduates through university social media channels.

Campus decisions in the spring had significant financial implications, and families had definite opinions about what actions institutions should take in this unprecedented situation. As families struggled with lost jobs and income and concerns for their students who were experiencing the same, they were persistent in requesting 
refunds for housing, dining, parking, and tuition, with varying responses from institutions. The University of Alabama offered a prorated refund of housing, dining, and parking fees, allowing students and families to access refunds in various ways. The university also offered incentives for those who applied the refund to the fall 2020 bill. Families at all four institutions requested partial tuition refunds due to the change in instructional delivery, even though universities' expenses remained the same or increased with the shift to remote course delivery. Institutions struggled to balance financial implications with public and customer perceptions and their duty of care for students and families.

In between calls with families, family engagement professionals turned to each other for brainstorming and support more than ever before. Each interaction with a frustrated family member increased the need to connect with someone who understood the daily challenges of their work. NODA hosted virtual round table sessions for professionals to discuss orientation plans. AHEPPP, the professional organization for family engagement professionals, brought members together to commiserate and plan virtual programming and Family Weekends. These networking activities brought family engagement professionals new ideas and benchmarking information to help inform decisions and plans for moving forward. The pandemic strengthened the connection and professional network among this group of student affairs staff members.

\section{Preparations for Summer}

During the final weeks of the spring semester, institutions also weighed decisions about summer and orientation programming. By mid-April, many institutions concluded that safely hosting in-person orientation was not possible, particularly with travel restrictions and various state mandates related to gathering sizes and "Stay at Home" orders. The decision to move student orientation to a virtual setting became a priority to protect the recruitment and enrollment process. However, decisions about parent and family orientations were often secondary and varied. At Georgia State University, where the orientation office coordinates both the student and family aspects of orientation, family orientation was canceled due to limited time and human resources. The cancellation brought another set of decisions around connecting with and informing families without a formal program.

Institutions where separate offices coordinate the student and families programs may have had more bandwidth to implement both programs, but bandwidth did not always come with prioritized campus resources. At The University of Alabama, campus staff who specialize in distance learning designed the virtual student orientation experience; however, staff building the family orientation experience did not have access to the same resources. Family engagement professionals continued to juggle the demands of wrapping up the spring semester while new delivery methods were created. Designing new programs meant quickly getting buy-in from campus partners, determining delivery methods for different program components, and vetting technology. Family engagement professionals focused on clear communication of what to expect during orientation in a virtual environment while also communicating what the institution expected of students.

Virtual orientation for families had a variety of challenges. Aspects of student orientation can be mandated, becoming a priority for the student. Institutions cannot compel family members to participate, so our family programming had to be more flexible to accommodate families' situations while also providing comprehensive information that would reassure family members about their students' decision to attend the institution. Universities lowered fees in many cases still had to cover operational costs. Both Texas A\&M University and The University of Alabama frequently heard from families who falsely assumed that virtual programs cost no money to provide and, therefore, should be offered for free.

With lower orientation fees, no travel costs, and mostly on-demand content, more families could attend. However, the virtual environment was a deterrent for others because of Wi-Fi or computer access challenges 
or unfamiliarity with technology. It was also easier for families to unintentionally not participate in virtual orientation. The stress of life during the pandemic and the understandable focus on their student meant many families registered for orientation but never logged in or accessed the information.

The shift to virtual family orientation also provided significant space for innovation, the use of new technologies, and rethinking how and why we do what we do. The University of Alabama used this opportunity to introduce families to the technologies, like Blackboard or Canvas, that students would use for their future classes. Texas A\&M University used the parent and family communication platform to host orientation. Family orientation courses were built with the intent that families could revisit the material throughout their students' tenure on campus to lessen the pressure on participants to remember every detail presented in a one-time program. Online orientation courses allowed families to consume the information at their own pace, unlike in-person orientation, which is often described as "drinking from a firehose." The University of Alabama saw no decrease in satisfaction and preparedness in participant responses to the parent and family orientation evaluation from previous years, though a substantial number of participants never entered the course to see the evaluation link.

Finally, through the development of virtual family orientation, we were forced to identify which information or connections must happen in real time and which can be on demand. Institutions used many platforms to stream student panels and often used the chat feature to take questions, hosted virtual meet-ups for families to connect with one another, and kept a virtual help desk open to offer more personalized troubleshooting.

\section{Summer Through Fall}

For these four institutions, summer brought orientation implementation and continued institutional concerns about recruitment and enrollment. New and continuing families wanted to know what fall would look like and how the safety of their students would be maintained. As institutions made decisions about course delivery, on-campus housing, dining limitations, academic calendars, and COVID testing requirements, family responses were deeply divided. No matter the decision, some families believed the institutional plan to be too conservative or overreaching, while others believed the plan to be unsafe. Families had opinions about the very existence of the virus, the severity of the public health threat, and the efficacy of various mitigation measures. They believed that institutional plans were open to debate and expected their individual student's situation to be accommodated, no matter the request. Higher education professionals across campus again faced questions for which they did not yet have answers and defended plans they were often not a part of creating. COVID testing requirements, in particular, were a source of many questions and opinions and created a communication challenge for campus staff.

First-year families usually experience some level of anxiety in the fall, but all families experienced heightened anxiety in fall 2020. The number of students and families impacted directly by loss due to COVID increased, bringing a greater need for financial aid and mental health support. First-year families worried about their students' transition to college with programs and services being provided in alternate ways. They felt that their students had already been denied the spring of their senior year and were outraged that their students' first year of college would also be impacted. They had increased concerns about how their students would find community and develop a sense of belonging, especially when many traditional campus events and ways of gathering were not available. Returning families, still experiencing negative feelings about spring distance learning, worried the fall academic experience would again fall short. They expected and demanded an improved online learning experience for their students or a return to primarily in-person classes.

Many institutions restricted campus housing and limited or eliminated face-to-face classes. Colleges and universities where students returned to campus experienced spikes in infection cases, faced challenges in 
supporting students in isolation or quarantine housing, and attempted to reassure families as they guided their students through the challenges of COVID. Once again, the polarization of families' opinions was heard loud and clear via email and phone calls to anyone for whom they could find contact information.

\section{Summarizing the Impact on Family Engagement}

During a global pandemic, family engagement was an area where the right decision for some families was the wrong one for others. The polarized nature of families' sentiments makes it important to explore our approaches to family engagement at a more granular level. These institutions had a range of approaches that included asynchronous modules, webinars, virtual sessions, and other engagement strategies.

COVID-19 required us to think creatively and make decisions with ongoing impacts. AHEPPP partnered with the University of Minnesota to conduct a two-part study with 3,300 respondents to explore how family members navigated decisions in the context of COVID-19. The majority of parents (83.5\%) reported "their student's institution was taking the right steps to handle the situation," yet only $20 \%$ of respondents identified the institution's family engagement office as a resource for information, and $24.3 \%$ reported not knowing who to contact (Dworkin et al., 2020). These findings illuminate the challenges of virtual engagement and how supporting families during a pandemic impacts our work.

\section{Development Virtual Content and Experiences}

Creating virtual experiences for students was challenging and continues to be an area of significant interest at local, state, and federal agencies. The corresponding experiences we prioritize for parents and families are critically important but come with challenges. With students being the primary driver of enrollment, prioritizing institutional resources during the initial transition to virtual operations often left family engagement programs out of the discourse. The disconnection from decision making was compounded by the challenge of educating and convincing family members to access and navigate the systems and content created for them. While those challenges are significant, the concurrent opportunities resulted in a high return on the investment.

The primary benefits of a virtual approach, whether synchronous or asynchronous, are the education and familiarization they create. Families can consume at their own convenience, they become accustomed to the platforms they or their students will use going forward, they have ongoing access to the content, and the lower financial and time commitments enhance accessibility. The benefits and challenges speak to how virtual engagement impacted our operations this year and for many years to come as the new cohort of students and families progress.

\section{The Impact of Virtual Engagement}

The full impact of this change will not be fully understood for some time. While research has shown that modality can create equal or better outcomes when students have a choice, the choice of many students for inperson learning is not possible due to the ongoing global pandemic (Maynooth University, 2020). The impacts of virtual learning on students' retention, progression, and graduation will play out over the next several years. Similarly, the impact of pivoting to virtual spaces in parent and family programs is both immediately apparent and likely to have long-term implications. One immediate impact is that many offices lost the ability to gather contact information for parents and family members due to hosting programs virtually or being unable to serve this population overall specifically. Communicating with parents and family members has always been critical for both orientation and family engagement professionals, yet it has never been more integral than in a global pandemic. Increased communication created different results for campuses. While some institutions experienced decreases in open rates of email communication, the institutions profiled here saw growth or consistency in 
engagement. At Miami University, open rates for the first-year family and all-family newsletters increased by $9 \%$ and 5\%, respectively, over the previous year. The content of the newsletters was similar. Georgia State University also saw increased open rates in addition to increases in social media engagement (120\%), website visits (87\%), and emails and calls received from parents and families (91\%). High levels of open rates occurred at both Alabama and Texas A\&M, which speaks to the importance of communication and to the critical need for parents and families to connect to and feel engaged by their students' institution.

Programs and services also look different in a virtual age, including webinar series, virtual orientations, and other engagement opportunities. Leveraging technology to foster a sense of community contributed to achieving long-standing goals, despite COVID-19. For instance, the University of Alabama hosts various virtual meet-ups (regional and affinity groups), which facilitate engagement and community development without limiting attendees due to social distancing. Georgia State, however, decided to prioritize synchronous events for students and use the existing online module system developed pre-COVID to build out a separate, asynchronous track for family members. While the decision was the right one at the time, the impact will be felt for years to come. Membership of first-year families in the Panther Family Association is down 10\%, and giving is down $15 \%$. These two funding sources support the operations of Georgia State's family engagement team, illuminating the need to approach future cycles differently.

In contrast, Texas A\&M provided both asynchronous and synchronous options for families attending virtual orientation. Families accessed a series of modules that included information typically covered at orientation. These modules included a combination of pre-recorded presentations and articles with information regarding campus resources. Texas A\&M then hosted seven live Q\&A sessions each week. These sessions included New Student \& Family Programs staff, orientation leaders, and Parent and Family Advisory Council Members. Texas A\&M also offered a monthly live health and safety webinar with representatives from counseling, student health, and police staff. These live sessions allowed families to feel engaged with the orientation process and helped provide a quick response time to family questions.

The mix of virtual and in-person programs will likely be a part of life in higher education for the foreseeable future and may ultimately increase the impact of family engagement. Texas A\&M, for example, is one of the first in the country to take on that challenge, hosting a blended Family Weekend in spring 2021. Blended events will likely become a reality for many of our programs in OTR and family engagement.

\section{Moving Forward Post-COVID-19}

As we look ahead, it is important to grow from the insights, challenges, and impacts of COVID-19, which necessitated developing new programs and changing existing approaches. As we look towards an eventual return to normal, newly created virtual opportunities may allow us to serve our family members better. Increasing familiarity and comfort with video conferencing software, social media, and technology solutions allow creative approaches to executing programs in the immediate context and provide long-term opportunities to increase the impact of parent and family engagement in the context of orientation, transition, and retention.

Family engagement and OTR professionals must prepare now for their work after the pandemic. The primary area of focus should be supporting families who entered the institution during the pandemic. The immediate needs are to fill in existing knowledge gaps and foster belonging and community, typically done through in-person programming. The secondary area of post-pandemic focus is changing our work to incorporate what we learned in 2020-2021. Throughout this year, we found creative ways to engage families, educating them about our institution and their role in supporting their students while also connecting them with each other and building affinity for our institutions. Many lessons and new programs can be integrated 
into our work to enhance how we serve families. Family engagement and OTR professionals must work in close collaboration on both of these important fronts.

As noted above, some institutions connected with many fewer families because they did not gather contact information through orientation. In addition to missing information vital to supporting their new college student, those families may also miss resources and opportunities throughout their student's time at the institution. Finding creative ways to gather this missing contact information, possibly through their students, are important. New families are already asking questions about the information that has been common knowledge in previous years and is typically not considered in current communication plans. This knowledge gap will likely continue throughout their students' experience, though it will lessen over time as students progress away from topics typically covered in orientation and transition programming. We must identify the gaps in knowledge and the families with whom we are not connected and find ways to provide that information through established or new means. Tracking the inquiries of first-year families (e.g., phone calls, social media questions) is an informal method for identifying gaps. Institutions should also consider formal assessments of first-year families, comparing those responses to similar assessments conducted in previous years.

Like concerns about belonging and community for students, institutions must consider the gap for families of our students. This gap may manifest in many ways over several years, including lower event participation and decreased giving by families, which is often crucial to the budget of a family engagement program. Finding opportunities for families to engage with each other and staff at the institution, both virtually and in person, can foster belonging and community. Just as many institutions are planning specific programming and celebrations for second-year students in fall 2021, institutions should consider special programs or celebratory initiatives for their families who could not or did not participate in programs such as family weekends during their students' first year.

In addition to addressing the immediate needs of current families, we should also apply lessons and innovations from the pandemic to our post-COVID work. Opportunities for more meaningful and sustained family engagement are available, and we can build on new collaborations created out of necessity in 20202021. Many families developed increased trust for and satisfaction with the institution during the pandemic, particularly around crisis communication and student health and safety (TorchStar Education, 2020). Building on that trust moving forward should be an important goal.

The rapid and widespread adoption of virtual engagement platforms provides many opportunities for new family engagement initiatives. Community building no longer must rely primarily on being in the same physical space at the same time. Events that happened during an orientation session or during the year on campus can now include a larger number of family members. Before 2020, we may not have expected families of incoming students in a certain program (such as cohort programs) to all attend the same orientation program. Hence, opportunities to connect them with each other were nonexistent. However, virtual gatherings allow families with commonalities to meet and connect with each other and staff on campus. This engagement can be particularly meaningful for families of marginalized or underrepresented populations. Regular virtual gatherings of families of Black students at a PWI or families of first-generation students can foster a community of support and a sense of belonging. The University of Alabama successfully held affinity-group programs during the pandemic, and the opportunity is readily available across our field.

Additionally, many institutions hosted virtual Q\&A sessions for families, especially as a part of the orientation process. Continuing to host such sessions throughout the summer and academic year gives families ongoing options for asking questions and may foster a sense of trust for the institution. Live streaming graduations and awards programs, done to a limited extent previously, was almost universally implemented as 
campuses recognized the need for all-virtual ceremonies. Making this standard practice will allow more family members and friends to join in the celebrations and recognition without the need to travel to campus.

Many institutions created other virtual programming for families, including virtual adaptations of family weekends/days. The range of engagement opportunities included synchronous events, asynchronous social media competitions, educational content, and ways to enjoy the community around the institution safely. Some institutions created packages of content, allowing families to create their own family weekend at a time convenient to them, with low to no fees. These programs remain applicable even after institutions return to hosting in-person events. Broadening access to a previously location- and time-bound event, many of the asynchronous ideas can be enjoyed at any time throughout the year at a lower cost to families, leading to higher overall engagement and fostering affinity for the institution.

Strategies that led families to trust the institution to educate and protect the health of their students (TorchStar Education, 2020) must not be discarded. Many institutions communicated with families more frequently than ever before and provided increased transparency because the fluidity of the pandemic demanded it. Families may expect increased levels of communication and transparency in the future, and institutions should consider how they will fulfill those expectations. Further engaging families in a transparent way will foster general trust while also better equipping them to support their students.

New partnerships and lines of communication forged during the pandemic, often out of necessity, should be maintained if they can lead to better experiences and support of families. For example, the need to communicate with families and transmit feedback from families may have opened new direct lines of communication between family engagement or OTR professionals and key individuals on campus. The relationship between Parent \& Family Programs and the provost's office at Miami University developed out of necessity: answering specific questions about course modality discrepancies. Yet, the relationship can benefit both offices beyond the pandemic. Maintaining these connections will ensure that families and their experience continue to be considered in decision making and communication strategies. These partnerships can also lead to new opportunities when we return to more face-to-face work.

\section{Conclusion}

The COVID-19 pandemic upended the "this is just how we do things" mentality on campuses. It forced family engagement and OTR professionals to reflect on and, in some cases, rethink how we engage and educate the parents and family members of our students. Families remain vital partners in supporting students' wellbeing and success. This period heightened the active role of many families as they cared for their students' health and advocated for their college experience. In addition to filling the gaps in knowledge and experience that COVID-19 created for current, particularly first-year, families, we must leverage the new strategies and tools used to engage families during this time to improve the programs and services for families of future students as well. Improving service delivery is what students and their families will expect of us and our duty as educators. 


\section{References}

Carney-Hall, K. C. (2008). Understanding current trends in family involvement. In K. C. Carney-Hall (Ed.), Managing parent partnerships: Maximizing influence, minimizing interference, and focusing on student success (New Directions for Student Services, No. 122, pp. 3-14). Wiley. https://doi.org/10.1002/ss.271

The College Crisis Initiative. (2020). Institutional Response to COVID-19 - Spring 2020 [Dashboard]. Retrieved from https://collegecrisis.shinyapps.io/dashboard/.

Dworkin, J., Cai, Q., \& Savage, M. (2020, October). COVID-19: College parents speak out. Retrieved from https:// innovation.umn.edu/college-parent/wp-content/uploads/sites/8/2020/10/College-Parents-Speak-Out_ Final-ReportOct2020.pdf

Forbes, K. J. (2001). Students and their parents: Where do campuses fit in? About Campus, 6(4), 11-17. https:// doi.org/10.1177\%2F108648220100600403

Gentzler, A., Oberhauser, A., Westerman, D., \& Nadorff, D. (2011). College students' use of electronic communication with parents: Links to loneliness, attachment, and relationship quality. CyberPsychology, Behavior \& Social Networking, 14(1-2), 71-74. https://doi.org/10.1089/cyber.2009.0409

Kiyama, J. M., Harper, C. E., Ramos, D., Aguayo, D., Page, L. A., \& Riester, K. A. (2015). Parent and family engagement in higher education. ASHE Higher Education Report, 41. https://doi.org/10.1002/aehe.20024

Maynooth University. (2020, May 28). MU research highlights concerns of primary school principals linked to COVID-19. https://www.maynoothuniversity.ie/news-events/mu-research-highlights-concerns-primaryschool-principals-linked-covid-19

Monroe, A., Myrick, K., \& Preston, D. (2020, August 13). Perceptions of the parents of college students after COVID-19. Education Insights Blog. https://www.ruffalonl.com/blog/enrollment/perceptions-of-theparents-of-college-students-after-covid-19/.

Mullendore, R. H., \& Banahan, L. A. (2005). Designing orientation programs. In M. L. Upcraft, J. N. Gardner, \& B. O. Barefoot (Eds.). Challenging and supporting the first-year student: A handbook for improving the first year of college (pp. 391-409). Jossey-Bass.

Savage, M. (2008). Developing, staffing, and assessing parent programs. In K. C. Carney-Hall (Ed.), Managing parent partnerships: Maximizing influence, minimizing interference, and focusing on student success (New Directions for Student Services, No. 122, pp. 67-79). Wiley. https://doi.org/10.1002/ss.276

TorchStar Education. (2020, August 18). The parent/family perspective (Research Brief No. 5). https://www. torchstared.com/covid 